\title{
Entre los carnavales y el teatro de ópera. Sociabilidades en una pequeña ciudad, Zárate, Argentina (1880-1930)
}

\author{
Between the carnivals and the opera house. Sociabilities in a small city, Zárate, Argentina (1880-1930)
}

Mariela Ceva

DOI: https://doi.org/10.24215/2314257Xe112

CONICET-CIS/IDES-CONICET, Argentina

mariela.ceva@gmail.com

Recepción: 21 Marzo 2019

Aprobación: 18 Febrero 2020

\section{RESUMEN:}

Desde fines del siglo XIX Argentina fue atravesada por un proceso de cambio continuo, acelerado y constante en su sociedad y economía. En este caso el tema es abordado desde las diversas manifestaciones musicales y teatrales existentes en la ciudad de Zárate, provincia de Buenos Aires, Argentina. A partir del análisis de la prensa local y de los libros de actas y memorias de la asociación de Socorros Mutuos italiana es posible percibir la persistencia, simultaneidad y la transferencia de tradiciones culturales y de referentes entre los diversos espacios de sociabilidad

Palabras clave: Teatros, Sociabilidad, Cultura, Música.

\section{Abstract:}

From the end of the 19th century, Argentina was crossed by a process of continuous, accelerated and constant change in its society and economy. In this case, to approach the subject we have chosen from the various musical and theatrical events in in the city of Zárate, province of Buenos Aires, Argentina. From the analysis of the local press and the sources of the association of Socorros Mutuos Italiana, it is possible to perceive the persistence, simultaneity and the transfer of cultural traditions and referents between the different spaces of sociability

KEYWORDS: Theaters, Sociability, Culture, Music.

\section{INTRODUCCIÓN}

Desde fines del siglo XIX Argentina fue atravesada por un proceso de cambio continuo, acelerado y constante en su sociedad y economía. Numerosos autores han identificado esa transformación con el proceso de modernización. ${ }^{1}$ Esta modernización se vería expresada en diversos ámbitos, entre ellos el cultural. Entre sus indicadores se encontraban el crecimiento poblacional, producto de la fortísima inmigración ultramarina; la incorporación de nuevas tierras, la apertura al comercio internacional, la llegada de capitales extranjeros, la urbanización, el tendido ferroviario, la organización político-administrativa, el desarrollo del mercado interno, el desarrollo de la prensa y de la industria editorial, y la aparición de imágenes y publicidades referidas a un nuevo estilo de vida considerado moderno, ${ }^{2}$ y a nuevos consumos culturales. Sin embargo, la renombrada modernización no fue ni tan lineal ni tan homogénea en el territorio nacional como podría suponerse, incluso quizás fue menos virtuosa de lo esperado.

En este caso para acercarnos al tema hemos elegido abordarlo desde las diversas manifestaciones musicales y teatrales presentes en un ámbito del interior de la provincia de Buenos Aires, Argentina. El estudio parte desde la reconstrucción de la sociabilidad ${ }^{3}$ de una pequeña ciudad, Zárate, de escaso tamaño pero de fuerte potencial económico, que permitió crear entre 1885 y 1930 una sociedad civil con numerosas instituciones, diferentes espacios de distracción y nuevas formas de relacionarse.

Para ello se recurrió a una variedad notable de fuentes: censos nacionales y provinciales, la prensa de la ciudad de Zarate, revistas teatrales de circulación nacional e internacional, los libros de actas y memorias 
de la Sociedad de Socorros Mutuos XX de Settembre, y las Actas del municipio de la ciudad, además de digestos y resoluciones locales. La combinación de este repertorio de fuentes, junto a una serie de trabajos de investigación previos desarrollados por la Asociación Amigos de Zarate, ${ }^{4}$ permite reconstruir una mirada a partir del mismo municipio y de la Sociedad de Socorros Mutuos, pero articulada con un contexto cultural más amplio y complejo. Por ejemplo, a partir de esas fuentes es posible observar cómo disposiciones municipales potenciaban o encuadraban las actividades de los vecinos, así como también visualizar cómo ese mismo municipio o sus representantes - por ejemplo, el intendente- gestionaban o posibilitaban actividades socioculturales de artistas y grupos musicales de renombre internacional. Asimismo, ese cruce de información expone la complejidad que significó, también en pequeñas ciudades del interior, la confluencia y el tránsito de actividades a los nuevos modos culturales de inicios de siglo XX.

Ciertamente, un recorrido por la conformación de esa sociabilidad zaratense permite apreciar alguna de las cuestiones constitutivas del proceso de cambio y de modernización, y visualizar cómo y de qué forma las diferentes expresiones culturales y los distintos actores fueron transfiriendo, intercambiando e integrando distintas experiencias, algunas consideradas más modernas o acordes a los nuevos tiempos de la modernidad. Uno de los cambios más importantes de una nueva imagen de civilización fue la difusión de salas de espectáculos. Todo esto expresaba también un orden social nuevo en el que la movilidad social, o al menos la autopercepción de la misma, contribuía de modo contundente a la imagen optimista de fin de siglo.

\section{Zárate: Una CiUdad industrial en la Buenos Aires rural}

Zárate, una localidad situada a menos de 100 kilómetros de la Capital Federal, recién fue considerada ciudad en 1909. Sin embargo, desde hacía algunos años ya tenía un rol importante en la provincia de Buenos Aires (Ceva, 2018). En primer lugar, tenía un puerto natural, el primero en el ingreso a las aguas del río Paraná. No era solo un puerto, era uno de los más protegidos del litoral, dado que estaba resguardado por las barrancas y por las islas. Asimismo, disponía de un gran movimiento comercial (Baccino y Sorolla, 1997). En segundo lugar, mostraba para fines del siglo XIX una activa vida económica; sus recursos podían equipararse fácilmente con los de Quilmes, Matanza o Baradero (Ferrari, 1996) -ciudades con fuerte crecimiento en la época-. También contaba con variadas industrias -lo que era poco común para una localidad del interior de la provincia de Buenos Aires- y además tenía aduana propia. En tercer lugar, aunque no es el único caso, habían surgido en ella una variedad notable de asociaciones culturales y sociales, muchas de las cuales eran sociedades de socorros mutuos, con referentes que procuraban consolidarse en el espacio mutual, pero también en las esferas políticas locales. Todo ello se cruzaba con un crecimiento exponencial de una población de los más diversos orígenes.

Ciertamente, el crecimiento económico de Zárate conllevó numerosas transformaciones sociales y espaciales. Si durante los primeros años del siglo XIX se observa una Zárate dedicada a la explotación agropecuaria, para fines del mismo su perfil se orienta hacia las actividades fabriles. Desde 1873, el puerto de Zárate había sido habilitado para el comercio interior como aduana. Asimismo era un lugar de paso obligado entre Buenos Aires y las provincias mesopotámicas. ${ }^{5}$ Todo ello permitió un importante crecimiento, que se vio potenciado cuando durante los primeros años del siglo XX comenzó a comerciarse lo producido por los frigoríficos que se habían instalado en la zona (Baccino y Sorolla, 1997).

Ya desde principios de siglo la ciudad contaba con 106 establecimientos industriales (Ferrari, 1996). El asentamiento industrial fue prefigurando la radicación de los trabajadores en determinadas zonas de la ciudad y sociabilidades diversas. La presencia de estos reductos industriales ${ }^{6}$ desde fines del siglo XIX nos muestra una ciudad con diversos matices, algunos de ellos reflejados en las siguientes impresiones: por un lado, un periódico de la campaña expresaba: “... una persona que llegaba días pasados a Zárate, nos refería con admiración los progresos que realiza día a día ese pintoresco pueblo de nuestra campaña" ${ }^{\text {; }}$; por otro lado, 
otros reflejaban sus temores respecto a la ciudad: "tiene una sociedad culta, aunque anarquizada y dividida por el espíritu de los partidos" ${ }^{\text {. }}$

Ambas realidades se acoplaban perfectamente con la diversidad de industrias y con el notable crecimiento poblacional de la zona. Como se observa en el gráfico $\mathrm{N}^{\circ} 1$, en el término de diecinueve años, entre 1895-1914, su población casi llega a duplicarse, y en ambos momentos presenta un elevado índice de extranjeros: $41 \%$ en $1895^{9}$ y $38 \%{ }^{10}$ en 1914 .

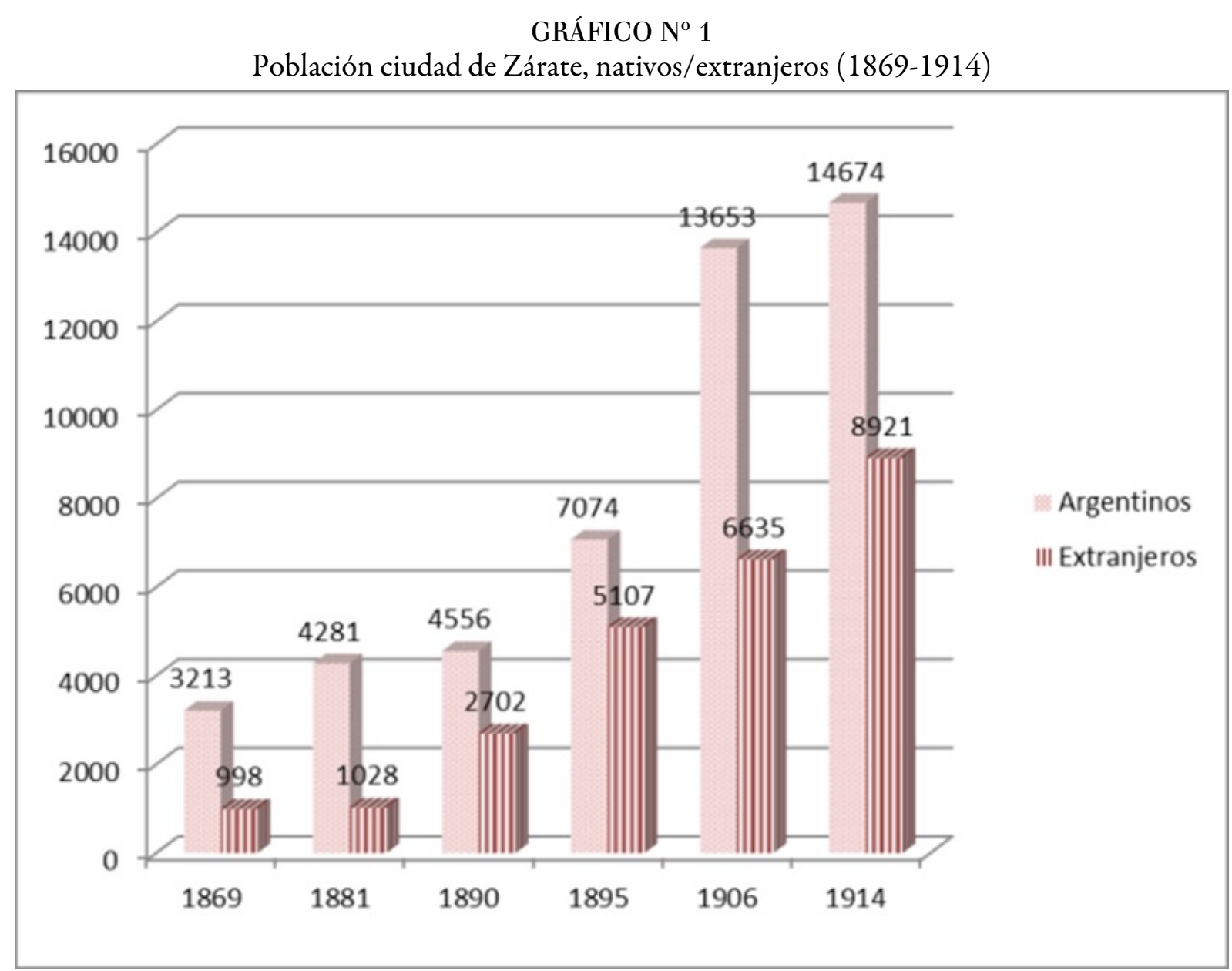

Fuente: Elaboración propia con base en datos de: Censo Nacional de Población, Rpca. Argentina 1869, Buenos Aires; Silvia Irene Baccino, Inmigración y Arquitectura en Zárate, extraído de http://www.enlacecritico.com/destacados/inmigracion-y -arquitectura-en-zárate; Vicente, Botta, op.cit, p.213; 3er Censo Nacional de Población, Tomo III, Rpca. Argentina, p. 167

Ciertamente, este componente extranjero trajo consigo la aparición entre 1880 y 1910 de numerosas sociedades de socorros mutuos de inmigrantes (Botta, 1948) y el establecimiento de viceconsulados. ${ }^{11}$ Este surgimiento de asociaciones ${ }^{12}$ o furor asociacionista no es propio de Zárate; responde a una tendencia nacional vinculada a las necesidades sanitarias, educativas y recreativas de la población recién llegada, acentuada en espacios pequeños - como el de esta ciudad-, donde los reductos de sociabilidad eran escasos. Vinculados a ellos, comienzan a asomar un grupo de inmigrantes que se destacaban en diversas actividades culturales y que buscaban consolidarse a través de ellas como referentes sociales. Entre ellos se destacan los italianos Dionisio Ferrari, Giacomo Filippone, Ernesto De Michelis, Eduardo Buscaglia, Adriano Roncaglia, Felix Distasio, Giusseppe Piccirelli (Poletti, 2000). La mayoría son referentes que inician su actividad hacia inicios del siglo XX, a los que encontraremos consolidados social, política y económicamente para la década del veinte. Todos ellos tienen pertenencias múltiples, circulan por diversas asociaciones y alternan sus cargos no solo con connacionales sino en instituciones multiétnicas (Ceva, 2018). 
Claramente, en una comunidad con 12.000 habitantes era inevitable la interrelación entre asociaciones y desde luego entre personas. Esa circulación entre espacios y sociabilidades permite ingresar al tema de cómo fue el pasaje y/o la transformación entre los diferentes géneros musicales y artistas. Asimismo, es sabido que las instituciones denotan rasgos o formas de activar sobre lo social de manera diversa en las diferentes épocas; en ese sentido, el caso de Zárate nos permite profundizar en cómo formas de diversión propias del siglo XIX se mantienen hasta entrado el siglo XX y se cruzan en los mismos espacios con nuevas formas, consideradas más modernas o civilizadas.

\section{DE CARNAVALES, VELADAS DANZANTES Y BANDAS DE MÚSICA}

Entre finales del siglo XIX y las primeras décadas de 1900, los espectáculos en los espacios públicos alcanzaron gran popularidad. Los había de todo tipo: carnavales, corsos, murgas, fiestas musicales en plazas y representaciones teatrales. Claro está que había diversiones públicas más deseadas que otras y que aquellas fueran las que desde el Estado se intentaba respaldar y simultáneamente reglar a través de normas para encuadrarlas dentro de lo que era considerado un comportamiento civilizado. Como ha planteado Pilar Gonzalez Bernaldo (2007), desde la primera mitad del siglo XIX se presentaba al Estado una contradicción generada entre, por un lado, la necesidad de respaldar las expresiones de sociabilidad, porque ellas implicaban la civilización y, por otro lado, la obligación de rechazar otras por considerarlas incivilizadas, o por considerar que provocaban una degradación moral del pueblo. Según ha demostrado Carlotta Sorba (2001) para el caso italiano, el teatro era considerado como un objeto necesario al decoro de la ciudad y al honesto entretenimiento de los ciudadanos. En ese sentido, el teatro tenía una utilidad social y al mismo tiempo una moral. Por supuesto que existían otros espacios con utilidad social, aunque quizás con menos utilidad moral o pedagógica.

Esta distinción entre espacios deseables y menos deseables y el rol del Estado en su promoción o desaliento obviamente no era nueva. De diferente forma y para diferentes sitios la cuestión había transitado todo el período posrevolucionario. Jorge Myers (1999) ha propuesto, hace ya varios años, cinco grandes zonas de la experiencia social y cultural rioplatense: 1- la sociabilidad doméstica y semiprivada, 2- los espectáculos públicos y el uso de los espacios de esparcimiento urbanos, 3- la interacción semipública de los cafés, 4- la actividad corporativa, y 5 - las asociaciones políticas o semipolíticas. ${ }^{13}$ Consideramos que esta clasificación permite identificar, por un lado, las características específicas de cada uno de esos espacios sociales, y, por otro, profundizar en la importancia general y relativa de cada una de ellas en una pequeña ciudad del interior del país.

Primeramente nos centraremos en la segunda de ellas, es decir, en los espectáculos públicos y en el uso de los espacios de esparcimiento urbanos. En Zárate podemos identificar que existía una delimitación espacial en el esparcimiento. En primer lugar, el afuera; allí dos son los lugares de expresión: la vía pública y la vía fluvial. En el primero se realizaban los carnavales y los encuentros musicales y teatrales en la plaza pública. En el segundo, se realizaban los paseos en barcazas y los picnics a orilla del río.

Los espectáculos al aire libre se concentraban en la plaza principal de la ciudad y podrían ser divididos en dos: aquellos que solo tenían lugar una vez al año y aquellos que se realizaban casi cotidianamente, como bailes y música durante los fines de semana. Sin embargo, a pesar de esta división, es preciso señalar que existía entre ellos una complementariedad temporal y una fluida circulación de actores, músicos y bandas. Quizás el más representativo de todos los espectáculos públicos haya sido el carnaval anual. ${ }^{14} \mathrm{El}$ carnaval era una diversión reglamentada por el municipio, que era el encargado de estipular desde los horarios hasta los elementos que podrían portarse. Como ha sido señalado por varios estudiosos, a partir de los ochenta el Estado comienza accionar sobre las diversiones que se desarrollaban en el espacio público, entre ellas, los carnavales (Gayol, 1993). En el caso de Zárate, el corso se iniciaba en la calle Justa Lima de Atucha con una bomba de estruendo. Allí se ubicaba el palco en el que se ubicaban las autoridades municipales, la comisión organizadora y el 
jurado. El jurado estaba encargado de elegir los premiados según tres categorías: mejor vehículo, vehículo más adornado y mejor comparsa. ${ }^{15} \mathrm{El}$ corso contaba con el desfile de carrozas, carruajes variados y comparsas con bandas de música (Baccino y Sorolla, 1997). Las comparsas carnavalescas también debían portar el permiso de visado, que era una tarjeta sellada, numerada y que debía llevarse a la vista. Se tramitaba en el municipio, y tenía un valor de 50 centavos. ${ }^{16}$ Para obtener este permiso eran los presidentes de las sociedades de socorros mutuos quienes debían presentarse en la Intendencia, para brindar los datos que fueran necesarios y hacerse responsables de las alteraciones que pudieran presentarse. ${ }^{17}$

A pesar de todas estas disposiciones municipales, las reuniones propiamente dichas para programar el carnaval se realizaban en la Sociedad Argentina de Socorros Mutuos. ${ }^{18}$ Las sociedades de socorros mutuos cumplían múltiples funciones: daban protección a los trabajadores y los asistían en situaciones de enfermedad o falta de trabajo y de muerte. También eran espacios de sociabilidad, de refuerzo de los vínculos entre los inmigrantes y sus descendientes y espacios de intercambio de las élites económicas, políticas e intelectuales de los distintos grupos locales, regionales e incluso nacionales (Bernasconi y Ceva, 2018). Estas asociaciones fueron mayoritariamente constituidas por extranjeros pero también las había de argentinos. En el caso de la Sociedad Argentina de Socorros Mutuos de Zárate estaba conformada por renombrados vecinos, muchos de los cuales formaban parte del gobierno municipal motivo por el cual no es sorprendente que justamente ella fuera la encargada de organizar el carnaval. En este caso la sociedad era la encargada de recaudar fondos, de establecer el orden de presentación de las comparsas, de velar por el decoro, la moral pública y también de seleccionar la música que se utilizaba durante el desarrollo del desfile. Durante los días previos se sucedían los avisos de venta de máscaras, pomos, y se adelantaba que la actividad sería "brillante" y que se presenciaría un "Momo triunfante" 19 . El encuentro representaba, en una población del interior de la provincia de Buenos Aires, un espacio de integración y celebración; así se observaba en las calles, que desde el día del inicio la población en su conjunto se lanzaba al grito de "te conozco mascarita", como forma de iniciar la interacción entre los vecinos. A partir de la prensa local es posible percibir la importancia y el impacto que el carnaval generaba en la pequeña aldea. Numerosos eran los avisos con los precios de los antifaces y las serpentinas, los lugares de venta de lo necesario para la celebración e incluso un listado de las calles que se encontrarían adornadas para el paso de las carrozas. Lamentablemente, la información disponible no permite reconstruir con detalle quiénes participaban ni tampoco brinda información sobre cómo se organizaban las comparsas a su interior, ya que para su reconstrucción solo contamos con un digesto municipal de la reglamentación en el que la única preocupación es el control. A través del reglamento se enfatizaba la necesidad de prohibir el uso del agua o líquidos, se establecía un horario específico para el juego con pomos y se señalaba la prohibición del uso de disfraces que hicieran referencia a militares y a vestiduras sacerdotales. ${ }^{20} \mathrm{Si}$ bien los carnavales exponían al peligro del descontrol su reglamentación, la presencia policial y la exposición pública en la prensa contribuían a que se señalara que: "la enorme concurrencia dio pruebas de una cultura sin límites, pues no se produjo en tres noches de corso el más insignificante incidente” ${ }^{21}$.

Su importancia también radicaba en que durante los días de carnaval desfilaban todas las bandas, muchas de ellas dirigidas por italianos: "la banda de la fábrica La Papelera Argentina; la banda La Zarateña; la banda del Cuerpo de Bomberos Voluntarios; la Blanco y Negro; La Flor, la Campera y la banda Estrella del Oriente" (Baccino y Sorolla, 1997).

A esta actividad, que se llevaba a cabo una vez al año, se sumaban las que se realizaban los fines de semana, por ejemplo, bailes y música en la plaza principal. Los bailes, además de realizarse en los clubes y salonesteatros, también se hacían en los hoteles. Así, por ejemplo, es común observar la publicidad del Nuevo Hotel del Globo, en la que se ofrecían salones para bailes y banquetes. ${ }^{22}$ Aunque no solo se realizaban en el centro de Zárate sino también en los alrededores, como en el Club Las Palmas, hacia el que grupos de vecinos se trasladaban desde otras localidades. ${ }^{23}$ 
Es muy común observar en los periódicos de la época las invitaciones a participar de noches de música en la plaza de la ciudad y en los pueblos cercanos. Los encuentros se realizaban al atardecer; las crónicas describen a una nutrida asistencia de público para presenciar los conciertos que realizaba la banda de música L'Abruzzese, ${ }^{24}$ que presentaba un programa muy variado. ${ }^{25}$ Según el cronograma del año 1902, la banda se presentaba en un principio todos los días jueves de cada semana, pero luego, debido a la gran afluencia de público, comenzó a ofrecer los conciertos los domingos por la tarde.

Es común observar en la prensa local avisos anunciados como "Música en la Plaza”; así, por ejemplo, en 1903 se señalaba lo siguiente:

Esta tarde a las tres y media concurrirá a nuestra plaza la banda de música L'Abruzzese que dirige el maestro Domingo Francesco donde ejecutará un excelente programa.26

Otra banda que también actuaba en la plaza pública era la Zarateña, entre su repertorio se encontraba la Traviata y el Trovador de Verdi. ${ }^{27}$ El programa comprendía una variedad notable de obras desde Gerardo Metallo $^{28}$ hasta Giuseppe Verdi. Es importante resaltar esta presencia de espectáculos líricos en pequeños pueblos y en espacios abiertos, ya que muestran los circuitos por los cuales circulaba el teatro considerado culto. $^{29}$

Por otro lado, se encontraban los espacios semipúblicos o el "interior", allí los lugares son varios: casas; bares/confiterías y salones/teatros. Sobre la diversión en las casas, se observa que la actividad principal eran las antiguas tertulias o veladas danzantes, tres o cuatro casas de familias renombradas de Zárate eran las indicadas para esos fines. Las reuniones sociales en las casas y palacetes eran asiduas y lo sucedido en ellas era reseñado en la prensa. En esos racconti se destacaba la importancia de las mismas por "dejar huellas perennes en el mundo social" y destacaban la "clase de elementos que la forman" ${ }^{\text {". }}$. Simultáneamente se describía la forma en la que se daban: primero llegaban todos los invitados, conocidos miembros de la sociedad local, entre los que se destacaban las "señoras", luego, los dueños de casa recibían amablemente a los invitados y se pasaba a escuchar a la orquesta que alternaba con presentaciones en piano para iniciar los bailes. Posteriormente, se realizaba un corte en el que se ofrecía un lunch para continuar con más orquesta hasta las tres de la mañana. Se presentaba una lista de los asistentes y también una ponderación sobre los músicos. Toda la descripción, ${ }^{31}$ desde la importancia del evento hasta la identificación de sus organizadores como "cumplidos héroes de torneos sociales", se publicaba en la primera plana de un semanario de amplia difusión, lo que da cuenta del impacto que esa transferencia de sociabilidades tendría sobre el conjunto de la sociedad o sobre la parte principal de la misma.

En cuanto a los bares y confiterías, todas las crónicas de la época refieren a la Confitería del Progreso, fundada por Antonio Di Lázzaro, como el sitio obligado para el encuentro social, cultural y político de la comunidad zarateña. ${ }^{32}$ La Confitería del Progreso también ocupaba un lugar central en el tejido urbano, frente a la plaza principal, y el punto de inicio de todos los desfiles y festejos institucionales de la ciudad.

Ahora bien, entre todos estos lugares existían -como se ha podido observar en la descripción previa-varios nexos, pero uno de los más importantes era la presencia en todos ellos de bandas de música o de integrantes de ellas que circulaban incansablemente entre esos espacios. Había bandas de todo tipo: bandas de fábrica, costumbristas de temas locales, militares, de la ciudad (Baccino y Sorolla 1997). Como puede observarse, en ese ambiente confluían las más diversas tendencias e influencias culturales. ${ }^{33}$

¿Cómo surgieron estas bandas? ¿Qué relación tenían con el mundo laboral?, ¿y con el Estado? Todos estos son temas sobre los que aún tenemos escasa información para profundizar. Sin embargo, es sabido que por ejemplo las fábricas tuvieron desde sus inicios una estrecha relación con la formación de bandas. La misma era una costumbre europea, con gran arraigo sobre todo en los países del norte. ${ }^{34}$ El caso belga es muy significativo, ya que en origen contaban con una fuerte tradición en la organización de las mismas en el interior de los ámbitos fabriles. Justamente en Zárate la primera banda que se organizó en una fábrica lo 
hizo bajo la dirección de un belga. Esta se encontraba entre los varios beneficios que la fábrica de papel La Argentina ofrecía a sus trabajadores. Son escasos los datos relacionados con la constitución de la misma y con la selección de sus músicos; lo que sí sabemos es que estaba conformada por 50 trabajadores y que era dirigida por el maestro José Cavazzoni. Incluso conocemos que este director había estado relacionado con la banda municipal de Mar del Plata.

El otro grupo de bandas eran las vinculadas a lo militar. En este caso puntual la banda del arsenal naval de Zárate ocupaba un lugar destacado en todos los festejos patrios y sociales. También actuaba en esos eventos la del Batallón 8 de Infantería. Como ya se ha señalado, todas ellas daban funciones en las plazas públicas.

Ciertamente, la participación de las bandas se daba en todos los ámbitos, incluso ellas tuvieron un rol protagónico cuando la sociedad zaratense se movilizó frente al conflicto limítrofe con Chile. ${ }^{35}$ Una de las manifestaciones más imponentes fue la realizada el 4 de diciembre de 1901, organizada por la Liga Patriótica local; contó con la presencia de "gente de todas las nacionalidades" y estaba destinada a brindar apoyo a Roca, presidente de la República Argentina. En esa oportunidad, un rol central fue el otorgado a la banda de música L'Abruzzese, que en un acto de apoyo a la soberanía nacional ejecutó el himno nacional argentino y a continuación el himno de Garibaldi (Devoto y Fernández, 1990). El episodio en parte se relaciona con una cuestión más amplia en torno a la construcción de redes de relaciones sociopolíticas entabladas desde muy tempranamente entre inmigrantes italianos y autoridades municipales. Un elemento a destacar es que el referente político indiscutido, por varias décadas, de la ciudad será Luis Güerci, ${ }^{36}$ un inmigrante italiano, arribado de pequeño a la Argentina. La actividad política de Güerci se había iniciado en el radicalismo para luego transferir lealtades (y presumiblemente su red de apoyos) hacia el Partido Conservador sin que su predominio se viera afectado. ${ }^{37} \mathrm{~A}$ esa red de relaciones y a la ubicación de su familia en puestos claves del municipio se sumaba la participación en las instituciones asociativas de la localidad, entre ellas en las asociaciones de socorros mutuos (Ceva, 2018). A través de este entramado se movilizaban y se enlazaban diferentes tipos de identidades políticas surgidas en torno a las asociaciones y a los líderes locales que se expresaban en mítines políticos o en movilizaciones relacionadas al nacionalismo y en numerosas actividades culturales. ${ }^{38}$

Esa infinidad de actividades artísticas desarrolladas en la comunidad nos hace suponer que existía en ese espacio un fuerte interés hacia lo cultural y musical. Asimismo, estos músicos de estos espacios populares y urbanos también transitaban por aquellos otros lugares más íntimos y privados y con nuevas versiones, como las mencionadas "veladas danzantes", desarrolladas en las viviendas particulares, en salones, e incluso en los teatros lo que generaba una circulación de estos referentes musicales y una tradición local musical. Ese interés musical en la ciudad comenzó a manifestarse más intensamente a principio de 1900. Uno de los primeros referentes fue Pedro Silvetti, ${ }^{39}$ quien formó la primera orquesta que ejecutó conciertos de repertorio escogido y clásico en reuniones sociales, culturales y de beneficencia en el pueblo (Botta, 1948).

Todas las bandas y esos espacios fueron, en Zárate, lugares de entrenamiento musical, pero la formalización de un espacio destinado a la formación de profesionales ocurrió en 1910 cuando se instaló el conservatorio de música Williams, anexo al de Buenos Aires, bajo la dirección del profesor Alfonso Butri. ${ }^{40}$ Con anterioridad a esa fecha había sido fuertemente promocionado el inicio de clases de piano, las mismas se encontraban a cargo de una joven, quien había cursado sus estudios superiores en la Academia Mozart, de la Capital Federal. ${ }^{41}$

Pero fue del conservatorio de Butri del que emergieron más referentes artísticos de Zárate, por ejemplo Juan Carlos Caisson, quien había obtenido a los 14 años su título de violín, cuyo maestro había sido Juan Elhert (Poletti, 2000). Justamente Elhert sería uno de los referentes musicales para el momento en que se inauguró el teatro Coliseo y se convertiría con los años en uno de los musicalizadores más renombrado de Argentina. ${ }^{42}$

Por su parte, Alfonso Butri, además de instalar el primer conservatorio en Zárate, era también empresario teatral y alquilaría durante varias temporadas el Teatro Italia, propiedad de la Sociedad de Socorros Mutuos 
XX de Settembre, para sus funciones. Posiblemente estos espacios, como el conservatorio y la escuela de música, pudieron haber sido aquellos "canales de modernidad" ${ }^{\prime 3}$, tanto por ser exponentes portadores de una mayor sofisticación musical y de una mayor profesionalización, pero también por aglutinar un capital específico destinado a la música con presencia en su interior de culturas de larga trayectoria.

\section{LOS TEATROS Y EL GRAN COLOSO}

Ciertamente esa actividad recreativa, musical y dramatúrgica tenía un fuerte anclaje en el fin del siglo XIX cuando comienzan a construirse en la ciudad los salones de recreación y los teatros. Sobre los salones y teatros, de la misma manera que las bandas, los había de todos los tipos. Según registros de la época en la Sociedad de S. M Operai Italiana, fundada en 1884, se ofrecían espectáculos de carácter lírico. Por su parte, la sociedad española de Socorros Mutuos había construido en 1898 el teatro Hispano (Baccino y Sorolla, 1997). En el teatro se ofrecían "noches de teatro" con un variado repertorio. ${ }^{44}$ Según se desprende de las crónicas de la época, contaba con una concurrencia variada. Entre el público se encontraban las familias más distinguidas de Zárate, ubicadas en los palcos, ${ }^{45} \mathrm{y}$ una platea "repleta de espectadores”. ${ }^{46} \mathrm{El}$ programa era:

de los que rara vez se confeccionan aun en los teatros metropolitanos, por la variedad y clase de números que los formaban y una "prolongada salva de aplausos estalló al finalizar. ${ }^{47}$

Por esa sala pasaron muchas compañías del género de la zarzuela, y otros. Allí también comenzaron a darse, en 1907, producciones cinematográficas, y ofrecía funciones musicales el Arsenal de Artillería de la Marina.

También se encontraba el Teatro Italia, edificio de la Sociedad Italiana de Socorros Mutuos, en el cual se dieron numerosos espectáculos, entre ellos de compañías circenses (Baccino y Sorolla, 1997). Si bien para el caso de la ciudad de Buenos Aires, Pasolini (1999) ha demostrado que la ópera y el circo se habían transformado entre 1870 y 1910 en los polos antagónicos que ofrecía la oferta teatral -ya que habían desarrollado prácticas de consumo específicas y de particulares significados a los géneros-, en el caso de Zárate se observa que en sus inicios estas salas de teatro de fin de siglo combinaban diferentes géneros. Era común observar la publicidad de piezas circenses en el salón o presentaciones populares de diversa naturaleza y luego piezas teatrales, sobre todo aquellas relacionadas al teatro musical, presentadas en nuevas formas acotadas a la sala teatral y con una combinación de obras musicales y piezas de concierto, y en ambos casos con la presencia de los mismos referentes culturales locales. Como también se ha observado para el caso italiano, en sus inicios el teatro de ciudad era un lugar no especializado, adaptado para albergar cualquier forma de espectáculo y de entretenimiento. Era un espacio diverso, que hospedaba de un lado un panorama espectacular -dominado por la curiosidad exótica y espectáculos de arte variada-, y que se basaban más en la exhibición que en la representación, y de otro lado, un único género denominado serio ${ }^{48}$-porque se encontraba codificado-, que en música se identificaba con el melodrama (Sorba, 2001).

Ciertamente debe señalarse que la introducción en los debates sobre las transiciones en el campo de la música se ve potenciada a partir de la relación de esta con la Nueva Historia y con una mirada interdisciplinar del proceso de difusión. ${ }^{49}$ Asimismo, el análisis desde la relación de qué se produce, quién lo produce y su contexto de producción se ve reflejado en la aparición de diversos estudios de caso sobre el tema. ${ }^{50}$ En ese sentido el caso de Zárate se encuentra en ese cruce, aunque se parte claramente desde un enfoque histórico.

En qué período se produjo esta transición o si estas convivieron en un arco temporal prolongado es tema que nos resta analizar, pero lo cierto es que hacia fines de 1890 la publicidad de ambas versiones se reiteraba en los periódicos de circulación local como también permanecía presente hacia fines de la década del veinte. Situación semejante se da en el caso de Brasil, donde se evidencia la circulación de los géneros musicales a través de los diversos ámbitos (Bellard Freire, 2004). 
Ya hacia fin de siglo se observan en Zárate actividades musicales de diferentes tipos en diversos espacios. La muestra de ello era la llegada frecuente de compañías de teatro lírico, dramas y comedias, zarzuela y variedades (Botta, 1948). En esos espacios teatrales las actividades podían ser la presentación de obras y también la realización de bailes. Pero el ofrecimiento musical no variaba demasiado. De hecho, la mencionada banda de música L'Abruzzese actuaba indistintamente en todos los salones y siempre ofrecía el mismo repertorio, aunque el público siempre era muy nutrido, lo que, según las crónicas, hacía preciso que se ampliara el número de plazas para satisfacer la demanda.

Esta necesidad de nuevos espacios se encontraba en sintonía con el boom teatral generado a partir de 1880, que tendría sede en la ciudad de Buenos Aires pero que se irradió hacia otras, como Montevideo, Rosario, La Plata. Muestra de ello fue la difusión de más de cuarenta títulos de revistas teatrales (Mazziotti, 1990). Junto a este proceso se da la llegada de compañías extranjeras. Ya hacia 1870 habían irrumpido las compañías italianas, tanto dramáticas como líricas, que congregaban un gran público que comenzaba a considerar que había géneros de mayor producción y jerarquía (Cilento y Sanz, 2002). El centenario, según algunos autores, parecía alentar el consumo teatral. De hecho, en la Revista Teatral para 1906 se señalaba: "la temporada teatral es inmensa; los artistas tienen fama mundial y las salas de espectáculos son más que confortables" (Cilento y Sanz, 2002). En Zárate, la aparición de salones de encuentros y de reuniones continuó durante la década del 10, como también la creación de otros teatros. Entre ellos se encontraba el Teatro Argentino, con capacidad para 1200 espectadores, cuyo propietario era Pedro Albano. ${ }^{51}$ Así, con el Teatro Argentino, hacia inicios de la década del veinte Zárate tenía tres teatros vinculados a diferentes grupos nacionales (los teatros Italia e Hispano -además del Argentino-, de características muy similares).

A los tres teatros existentes desde fin de siglo, que cumplían funciones variadas, y que quizás podrían identificarse con los denominados politeama $a^{52}$ europeos, se sumaría en la década del veinte el Coliseo, en este caso sí con una clara finalidad: convertirse en un teatro lírico. Al igual que el teatro Italia, el Coliseo, o "Gran Coloso”, como se lo llamaba, era propiedad de la Sociedad Italiana de Socorros Mutuos XX de Settembre. ${ }^{53}$

Hacia fines de la década del 10, con una población acostumbrada a espectáculos musicales, con la existencia de músicos y bandas de larga trayectoria artística, con disponibilidad de recursos económicos en una ciudad pujante, con la presencia de un contexto de expansión nacional de salas teatrales, y con una dirigencia en búsqueda de posicionarse en el ámbito político/social de la ciudad, surge la idea de la construcción de un gran teatro de ópera, en parte vinculado al interés teatral de los años veinte.

Al boom teatral de fines del siglo XIX e inicios del XX, con una notable presencia de compañías extranjeras, le había seguido un período de emergencia de un teatro nacional, en parte provocado por la interrupción durante la guerra de la llegada de artistas e intérpretes europeos. Los elencos que llegaban con asiduidad antes de la guerra habían dejado de hacerlo y recomenzaron en los años 20 con nuevas compañías y con algunas de las antiguas. Estas además introducían nuevas estéticas, muchas de las cuales se habían gestado en la década del 10 en Europa (Cilento y Sanz, 2002). Así, es posible observar en Argentina un resurgimiento teatral que combinaba compañías europeas con nacionales, las cuales se habían posicionado en la plaza argentina (Paoletti, 2015).

En el caso de Zárate, la iniciativa durante estos años parte de la asociación de socorros mutuos italiana. Desde 1918, algunos socios de la Sociedad XX de Settembre habían alertado sobre la necesidad de ampliar las localidades del salón-teatro Italia, que había sido destinado a representaciones teatrales y espectáculos cinematográficos, ya que era pequeño, no redituaba ganancias por su escasa capacidad y se encontraba alejado del centro. ${ }^{54}$ Durante estos años es común observar presentaciones líricas en el Teatro Italia, muchas de ellas locales, con integrantes de orquestas y bandas también locales, como es el caso de Silvetti, a quien hemos mencionado por su rol en los inicios del siglo XX (Ceva, 2018).

Este teatro había contado desde fines del siglo XIX con varias presentaciones de espectáculos líricos. Así, la Compañía Aymasso puso en escena la ópera Tosca, y fue destacada por la prensa local como "la notable 
compañía dramática italiana (...) notable por su elenco como por su repertorio" ${ }^{\text {. }}$. Esas funciones líricas tuvieron continuidad, ya que, por ejemplo, también en 1926, en ocasión de celebrar el 20 de setiembre, se presentaron dos grandes funciones líricas. El día 19 de setiembre se había presentado Madame Butterfly protagonizada por la soprano Adelina Agostinelli ${ }^{56}$ y el tenor Pedro Tabanelli, con profesores de orquesta de la Sociedad Orquestal de Buenos Aires y el maestro director y concertador Ferruccio Cattelani. ${ }^{57}$ El 20 de setiembre se presentó a su vez la orquesta Verdi dirigida por el ya mencionado Pedro Silvetti. ${ }^{58}$

Sin embargo, la escasa capacidad del teatro conllevaba dos problemas: por un lado le impedía a la sociedad obtener ganancias significativas, por otro lado, no alcanzaba a satisfacer las necesidades culturales de la población. Por ambos motivos los referentes de la Sociedad XX de Settembre remarcaban la importancia de construir un nuevo teatro, de mayores proporciones y especializado en espectáculos líricos.

El nuevo proyecto de teatro de ópera estuvo gestionado por una de las figuras más renombradas de la colectividad italiana de Zárate, Ernesto De Michelis, ${ }^{59}$ quien contó con el apoyo de destacados miembros de la comunidad. Este proceso demandó casi una década, ya que si bien fue pensado y proyectado hacia fines de los años 10, su realización recién se llevó a cabo para 1928.

A través de ese emprendimiento cultural es posible visualizar cómo esta elite étnica logró consolidarse socialmente en la ciudad de Zárate a través del uso de la alta cultura (el arte lírico) y la creación de un espacio para su expresión, su producción y su consumo (el teatro Coliseo), al mismo tiempo que buscaba representar la civilización y la modernidad. El discurso pronunciado durante la inauguración del nuevo teatro da cuenta de ello:

\footnotetext{
$\mathrm{Al}$ recordar hoy este largo camino trabajosamente recorrido, sembrado de obstáculos enormes, debo declarar francamente que no ha sido exenta de compensaciones morales, merced al concurso de tantas simpatías y voluntades que aseguraron el futuro desenvolvimiento, y no me mueve un sentimiento de personal complacencia, pero sí una profunda gratitud hacia mis cooperadores y una intensa satisfacción al constatar que esta gran obra, a más de su importancia material y de función social que está llamada a desempeñar, encierra una profunda significación ideal, cuya transcendencia no escapa al criterio de los presentes. $^{60}$
}

De Michelis buscó durante diez años (1918-1928) imponer un símbolo de la alta cultura y de la italianidad (representado en la ópera) en un espacio en el cual la comunidad italiana fue desde sus inicios mayoritaria, dentro del grupo extranjero. Pero a pesar de ser un emprendimiento de la colectividad italiana, el teatro Coliseo condensó prácticas culturales y musicales desarrolladas a lo largo de treinta años en la sociedad zaratense, y también se convirtió en el espacio de encuentro de los antiguos referentes musicales de Zárate, como Silvetti y Elhert y la banda L'Abruzzese.

Así el Coliseo era un espacio de sociabilidad que había sido posible porque se encontraba asentado en prácticas culturales que venían desarrollándose en la ciudad desde fines del siglo. Estas prácticas implicaban la presencia y circulación de artistas y repertorios de larga trayectoria en otros espacios -abiertos o cerrados-, y allí se plasmaban también los vínculos preexistentes entre ámbitos comunitarios, como por ejemplo la Sociedad de Socorros Mutuos XX de Settembre y las autoridades municipales.

\section{CONSIDERACIONES FINALES}

Entre los cambios que acarreaban los tiempos modernos uno no menor era la transformación de los espacios culturales. Entre ellos la proliferación de las salas de espectáculos fue uno de los cambios más significativos del período comprendido entre 1880-1930. Esto implicaba dos cuestiones: por un lado, la reproducción de espacios de sociabilidad más controlables por parte del Estado -en parte promovidos por él, o a través del apoyo a dirigentes mutuales, por ejemplo a los italianos de la XX de Settembre-; por otro lado, la adaptación de los actores que circulaban por los antiguos ambientes dedicados a la música hacia los nuevos más modernos. En el cruce de ambos se encuentran las adaptaciones y mutaciones que ambos sufrieron entre esos años. 
En ese sentido, un primer elemento se relaciona con la continuidad y circularidad de expresiones culturales. A partir de este estudio de caso se percibe que en el periodo comprendido entre 1880-1930 hay una primera etapa que se encuentra signada por expresiones culturales en los espacios públicos (plazas y avenidas) donde se desarrollan sobre todo carnavales, presentaciones de orquestas y de bandas. Hacia la década del 10 aparece un espacio destinado a la profesionalización o formalización de artistas musicales, y con él la aparición de veladas danzantes que combinaban su presencia en ámbitos abiertos y cerrados. Si bien durante todo el período se observa la presencia de teatros, estos son espacios más reducidos que podrían identificarse como salones destinados a presentaciones itinerantes o de alternancia y algunos de ellos para espectáculos líricos, que combinaban la presencia de compañías extranjeras con aquellos referentes musicales de bandas y orquestas locales. Hacia fines de los años 20 hace su aparición el teatro lírico Coliseo, aunque, paradojalmente, casi inmediatamente después de su inauguración comenzaría a ofrecer espectáculos con referentes locales y nacionales, pero con exposiciones de tango y con escasa presencia de ópera.

El segundo elemento se relaciona con la transferencia de espacios teatrales. La reconstrucción muestra una primera etapa 1880-1916 en la que se destacan salas-teatrales que se identifican con los grupos nacionales mayoritarios en Zárate. Así, hay un teatro Hispano, un teatro Italia y un teatro Argentino distribuidos en la ciudad. A lo largo de la década del 10 estos van perdiendo peso o se orientan a albergar algunas actividades. El Hispano dedicaba gran parte del tiempo a actividades festivas, y patinaje; el Argentino no reunía las condiciones para grandes espectáculos, y el Italia concentraba espectáculos líricos pero con muy pocas localidades. Será el Coliseo el que a partir del año 1928 se convertiría en "el teatro" de Zárate, y ya no será solo identificado como un teatro italiano sino como un símbolo de la ciudad.

Estas transformaciones se dan en el marco del propio proceso de modernización del país y en lo que tal vez se podría describir como el camino hacia un orden cultural considerado más "civilizado". Asimismo, en este estudio de caso es posible percibir la persistencia y simultaneidad de expresiones culturales entre el fin de siglo XIX y el principio del XX.

\section{ReFERENCIAS BIBLIOGRÁFICAS}

Agulhon, M. (1994). Historia Vagabunda. Etnología y politica en la Francia contemporánea. México: Instituto Mora. Baccino, S. y Sorolla, S. (1997). Era una vez... Zárate. Zárate: Ed. De los cuatro vientos.

Baccino, S. (2017). Inmigración y Arquitectura en Zárate. Enlace crítico. Recuperado de http://www.enlacecritico.co $\mathrm{m} /$ destacados/inmigracion-y-arquitectura-en-zárate,

Baily, S. (1982). Las sociedades de ayuda mutua y el desarrollo de una comunidad italiana en Buenos Aires, 1858-1918. Desarrollo Económico, 21(84), 485-514.

Barran, J.P. (1989). La cultura lúdica: el carnaval, paraíso de la materia. En Autor (ed.) Historia de la sensibilidad en el Uruguay: Vol. I. La cultura "bárbara", 1800-1860 (pp. 106-129). Montevideo: Ed. de la Banda Oriental.

Bellard Freire, V. (2004). Operas e Magicas em Teatros e Saloes no Rio de Janeiro-Final do Seculo XIX, Inicio do Seculo XX. Latin American Music Review, 25(1), 100-118. doi: https://doi.org/10.1353/lat.2004.0003

Bernasconi, A. y Ceva, M. (2018). Sociedades de Socorros Mutuos y teatros. Un ensayo de perspectiva comparada a partir de los casos de Gualeguay y Zárate. En Pereira E., Witt, M. A. e Truzzi, O. (Eds.), Imigração nas Américas: estudos de história comparada (pp. 161-197). São Leopoldo: Oikos-UNISINOS.

Botta, V. (1948). Historia de Zárate. 1869-1909. La Plata: Publicaciones del Archivo Histórico de la provincia de Buenos Aires.

Caimari, L. (2004). Apenas un delincuente crimen castigo y cultura en la argentina 1880 - 1955. Buenos Aires: Siglo XXI.

Castro, M. (2016). Católicos, librepensadores y anticlericales en el momento del Centenario: movimientos de protesta locales y política nacional. En Di Stefano, R. y Zanca, J. (Comps.) Fronteras disputadas: religión, secularización y anticlericalismo en la Argentina (siglos XIX y XX) (pp. 105-146). Buenos Aires: Imago Mundi. 
Mariela Ceva. Entre los carnavales y el teatro de ópera. Sociabilidades en una Pequeña CiUdad, ZÁr...

Cavaglieri, L. (2012). Trust Teatralediritto D'autore (1894-1910). La tentazione del monopolio. Pisa: Titivillus.

Ceva, M. (2010). Empresas, Inmigración y Trabajo en la Argentina: dos estudios de caso (Fábrica Argentina de Alpargatas y Algodonera Flandria). Buenos Aires: Biblos.

Ceva, M. (2018). Mediadores culturales y prácticas sociales en la construcción del Teatro Coliseo de Zárate, Argentina. Anuario Tarea, 5, 79-101.

Cilento, M. A. y Sanz, L. (2002). Compañías extranjeras 1884-1930. En Pellettieri, O. (Dir.) Historia del Teatro argentino en Buenos Aires. La emancipación cultural (1884-1930) (pp. 534-595). Buenos Aires: Galerna.

Corrado, O. (2010). Música y modernidad en Buenos Aires. 1920-1940. Buenos Aires: Gourmet musical.

Devoto, F. (2002). Nacionalismo, fascismo y tradicionalismo en la Argentina Moderna. Una historia,Buenos Aires: Siglo XXI.

Devoto, F. (2003). Historia de la inmigración en la Argentina. Buenos Aires: Sudamericana.

Devoto, F. y Fernández, A. (1990). Mutualismo étnico, liderazgo y participación política. Algunas hipótesis de trabajo. En Armus, D. (Comp.) Mundo urbano y cultura popular. Estudios de Historia social argentina (pp. 129-152). Buenos Aires: Sudamericana.

Di Nubila, D. (1960). Historia del cine argentino. Buenos Aires: Cruz de Malta.

Ferrari, M. (1996). Triunfos electorales conservadores en tiempos del oficialismo radical: ¿condicionamiento estructural o influencia política? Provincia de Buenos Aires, 1918-1930. En Melón, J. y Pastoriza, E. (Eds.) Los caminos de la democracia. Alternativas y prácticas politicas 1900-1943 (pp. 137-161). Buenos Aires: Biblos.

Ferrari, M. (2008). Los Politicos en la República Radical (1916-1930). Buenos Aires: Siglo XXI.

Gandolfo, R. (1992). Las sociedades italianas de socorros mutuos de Buenos Aires: cuestiones de clase y de etnia dentro de una comunidad de inmigrantes (1880-1920). En Devoto F. y Míguez, E. (Eds.) Asociacionismo, trabajo e identidad étnica. Los italianos en América Latina en una perspectiva comparada (pp. 311-332). Buenos Aires: CEMLA-CSE-IEHS.

Gayol, S. (1993). Ámbitos de sociabilidad en Buenos Aires: despachos de bebidas y cafés, 1860-1900. Anuario IEHS, $8,257-273$.

González Bernaldo de Quirós, P. (2007). Civilidad ypolitica en los orígenes de la nación argentina. Buenos Aires: Fondo de Cultura Económica.

Guiotto, L. (1979). La fabbricatotale. Paternalismo industriale e cittásociali in Italia. Milano: Feltrinelli.

Halperin Donghi, T. (1976). ¿Para qué la inmigración? Ideología y política inmigratoria en la Argentina (1810-1914). Anuario de Historia de América Latina, 13(1), 437-489

Hora, R. (2010). Historia económica de la Argentina en el siglo XIX. Buenos Aires: Siglo XXI.

Lobato, M. (2000). El progreso, la modernización y sus límites (1880-1916). Buenos Aires: Sudamericana.

Mazziotti, N. (1990). Bambalina: el auge de una modalidad teatral-periodística. En Armus, D. (Comp.) Mundo urbano y cultura popular. Estudios de Historia social argentina (pp. 69-89). Buenos Aires: Sudamericana.

Miguez, E. (2008). Historia Económica de la Argentina. De la Conquista a la crisis de 1930. Buenos Aires: Sudamericana.

Musri, F. (1999). Relaciones conceptuales entre musicología e historia: análisis de una investigación musicológica desde la teoría de la historia. Revista musical chilena, 53(192), 13-26. Recuperado de https://dx.doi.org/10.4067/S0 716-27901999019200003

Myers, J. (1999). Una revolución en las costumbres: las nuevas formas de sociabilidad de la elite porteña, 1800-1860. En Devoto, F. y Madero, M. (Eds.) Historia de la vida privada en la Argentina: Vol. I. País Antiguo. De la colonia a 1870 (pp. 111-146). Buenos Aires: Taurus.

Paoletti, M. (2015). Mascagni, Mocchi, Sonzogno. La Società Teatral e Internazionale (1908-1931) e i Suoi protagonista. Bologna: AlmaDL-Università di Bologna.

Pasolini, R. (1999). La ópera y el circo en el Buenos Aires de fin de siglo: Consumos culturales y lenguajes sociales. En Devoto, F. y Madero M. Historia de la vida privada en Argentina: Vol. II. La Argentina Plural, 1870-1930 (pp. 227-273). Buenos Aires: Taurus. 
Paul, D.C. (2016). Consensus and Crisis in American Classical Music Historiography from 1890 to 1950. The Journal of Musicology, 33(2), 200-231. Recuperado de https://www.jstor.org/stable/10.2307/26414204

Poletti, A. (2012). Zárate. Inmigración y familias. En Baccino, S. (Coord.) Colección Historia urbana y patrimonio de Zárate. Zárate: Ed. De los cuatro vientos.

Queirolo, G. (2018). Paradojas de género en la modernización argentina (1880-1970). Avances del Cesor, 15(19). 71-75. Recuperado de http://web2.rosario-conicet.gov.ar/ojs/index.php/AvancesCesor/index

Roverato, G. (1986). Una casa industriale. I Marzotto. Milán: Franco Angeli.

Sorba, C. (2001). Teatri. L 'Italia del melodrama nell 'ettà del risorgimento. Bologna: Il mulino

Suriano, J. (Comp.) (2000). La cuestión social en Argentina 1870-1943. Buenos Aires: La Colmena.

Trotta, F. (2018). Prejuicios, incomodidades y rechazos: música, territorialidades y conflictos en el Brasil. Anthropológica/año 36(40), 165-191. Recuperado de https://doi.org/10.18800/anthropologica.201801.008

Zeberio, B. (1999). Un mundo rural en cambio. En Bonaudo, M. (dir.) Nueva Historia Argentina: Tomo IV. Liberalismo, Estado y orden burgués (1852-1880) (pp. 294-362). Buenos Aires: Sudamericana

\section{Notas}

1 Los estudios históricos en Argentina han desarrollado extensamente las características e implicancias de la modernización en el país. Las miradas se concentraron no solo en el proceso económico que significó el ingreso de la Argentina en el sistema económico mundial a través de su integración por medio de sus exportaciones sino también en las transformaciones sociales (positivas y negativas) generadas por dicho fenómeno modernizador. En esos debates se encuentran presentes las implicancias que la modernidad conllevó sobre los aspectos culturales. Entre la importante bibliografía dedicada al tema puede verse: Zeberio, 1999; Míguez, 2008; Hora, 2010; Suriano, 2000; Queirolo, 2018; Lobato, 2000; Caimari, 2004.

2 El término moderno era utilizado en la prensa haciendo referencia a lo nuevo, o novedoso

3 El término sociabilidad será empleado según la definición ya clásica de 1966 y sus redefiniciones de 1988 de Maurice Agulhon.

4 La Asociación Amigos del Museo de Zárate Quinta Jovita ubicada en Ituzaingó 278, Zárate, viene desarrollando desde hace años una valiosa labor de recuperación y preservación de la documentación histórica de la ciudad.

5 Su papel de epicentro en la circulación había sido potenciado a través del tendido ferroviario en 1885 y aún más en 1908 con la inauguración de un servicio de ferry-boat, que realizaba el enlace entre Buenos Aires y la Mesopotamia. Sobre la situación estratégica de Zárate Cfr. Baccino \& Sorolla, 1997, pp. 38-47

6 Entre las industrias instaladas en Zárate: los frigoríficos: Las Palmas Produce Company Limited, 1880; The Smithfield and Argentine Meat Company Limited, 1903; River Plate, 1913; y Hall, 1916; Fábrica de Alcoholes; la compañía Fábrica Nacional de Dinamita; y la papelera La Argentina, luego llamada Celulosa Argentina.

7 El monitor de la campaña, de Exaltación de la Cruz, año 1871, Citado en Botta, 1948, p. 162

8 Ídem.

9 II Censo nacional de la República Argentina, 1895. Buenos Aires: Talleres Gráficos.

10 III Censo nacional de la República Argentina, 1914. Buenos Aires: Talleres Gráficos.

11 Para 1880 se establecen los viceconsulados de España y de la Banda Oriental del Uruguay; el italiano en 1893; la agencia consular italiana en 1899 y en 1904 el viceconsulado francés.

12 Sobre las sociedades de Socorros Mutuos en Argentina, Véase Devoto, 2003; Gandolfo, 1992; Baily, 1982.

13 Si bien el autor ha realizado el análisis para la primera parte del siglo XIX, aquí hacemos referencia a esa división en un sentido general. Vease Myers, 1999.

14 Sobre el significado del carnaval y su relación con un juego bárbaro, y como “desorden de los instintos”, véase Barrán, 1989.

15 El Debate, 15/02/1903, Año III, № 275, Zárate, p.1.

16 Ídem, p.1.

17 Ordenanza $N^{\circ}$ 98, 18/11/1913, Reglamentación de los festejos de carnaval, citado en Baccino \& Sorolla, 1997 p. 73

18 El Pueblo, 11 y 12/02/1903, Zárate

19 El Debate, 26/02/1903, Año III, No 278, Zárate, p.1.

20 Archivo Municipal Zárate, Ordenanza N 98, 18/11/1914.

21 Ídem, p.1.

22 El Debate, 26/12/1901, Año II, No 158, Zárate, p.3. 
23 Ídem, p.1.

24 La misma era dirigida por De Francesco.

25 El programa incluía: Marcha militar La Pelandra de J. Daray; Mazurka, Aida, N.N; Gioconda, Ponchielli; Media Noche, fantasía, Carlini; Vals Dalia, Marcha sinfónica, Libertad de los prisioneros italianos. Cfr. El Debate, 18/05/1902, Año II, No 197, Zárate, p.1

26 El Debate, 18/05/1902, Año II, No 197, Zárate, p.1.

27 El Debate, 20/01/1901, Año I, No 59, Zárate, p.1.

28 Gerardo Metallo fue un pianista, director y compositor ítalo-uruguayo (1871-1946).

29 Es importante señalar que esta presencia de bandas y espectáculos también se aprecia en el interior del país o en barrios de las principales ciudades. Cfr. Lobato, 2000; Ceva, 2010.

30 El Debate, 22/02/1903, Año III, № 277, Zárate, p.1.

31 Ídem, p.1.

32 La confitería El Progreso había sido fundada Antonio y luego fue administrada por sus hijos Enrique y Arturo, ambos italianos naturalizados. Cfr. Baccino \& Sorolla, 1997, pp. 106-107.

33 Sobre las ideas e influencias del temprano nacionalismo en Argentina, Véase Halperín Donghi, 1976; Devoto, 2002.

34 Numerosas industrias, sobre todo de gestión paternalista, contaban con bandas de música organizadas en su interior. Para el caso europeo véase, por ejemplo, Guiotto, 1979; Roverato, 1986; para el argentino, Ceva, 2010.

35 El Debate, 19/12/1901, Año II, No 154, Zárate.p.1.

36 Sobre la importancia de Luis Guerci en la construcción de lealtades políticas en Zárate. Cfr. Ferrari, 2008.

37 Sobre las disputas políticas identitarias en el Zárate de fin del siglo XIX. Cfr. Castro, 2016.

38 Sobre la relación entre Mediadores étnico culturales y prácticas sociales en Zárate, Cfr. Ceva, 2018.

39 Pedro Silvetti se instaló en Zárate en 1895 y abrió la primera farmacia de la ciudad.

40 Butri era profesor de música, agente teatral y director del conservatorio de Zárate. Cfr. Baccino \& Sorolla, 1997.

41 La profesora de piano era María Vallerga, Cfr. El Debate, 15/02/1903, Año III, No 275, Zárate, p. 1.

42 No existen referencias académicas sobre la biografía de Elhert; véase Di Nubila, 1960.

43 Expresión utilizada por Corrado, 2010.

44 Entre el repertorio se encontraban: Con permiso del mando, La Chiclanera; Para casa de los padres y Chateaux Margaux. Cfr. El Debate, 18/05/1902, Año III, No 197, Zárate, p. 1

45 El valor de los palcos era de \$ 8; palcos altos \$ 6; platea \$ 1.50 y paraíso \$ 1. El Debate, 10/12/1908, Año IX, № 867, p. 1.

46 El Debate, 9/04/1903, Año III, N²90, Zárate, p.1.

47 Ídem, p.1.

48 La denominación de "serio" hace referencia al contexto italiano del siglo XIX y en música es utilizado para hacer referencia a la ópera. $C f r$. Sorba; 2001.

49 Sobre la relación entre historia de la música e historia $C f r$. Musri, 1999.

50 Sobre casos de análisis de supervivencia y convivencia de expresiones musicales, para el caso estaodunidense, $C f r$. Paul, 2016; para el caso brasileño Cfr. Trotta, 2018.

51 Pedro Albano también había fundado en 1917 junto a su hermano Juan el periódico La Tarde surgido como consecuencia de la transformación en diario de la revista La Juventud fundada por ellos en 1915.

52 El término politeama es utilizado en el caso italiano para referirse de modo genérico a un teatro en el que se ofrecen espectáculos variados. Cfr. Cavaglieri, 2012.

53 La Unione Italiana XX Settembre- Societá di mutuo soccorso, italianitá e istruzione de Zárate resulta de la fusión en 1908 de dos sociedades de socorros mutuos italianas: la Sociedad Italia y la OperaiItaliani. Archivo Sociedad XX de Settembre de Zarate, Asociación Socorros Mutuos-Zarate (ASSM-Zárate), Contrato del 8 de febrero de 1921.

54 ASSM-Zárate, Memoria 1928, Zárate, p.1.

55 El Debate, 28/12/1901, Año II, No 159, Zárate, p. 1.

56 Adelina Agostinelli (1882-1954) fue una soprano italiana que desarrolló gran parte de su carrera lírica en la Argentina. Cfr. Ceva, 2018.

57 Nacido el 28 de marzo de 1867 en Parma, Italia. Compositor. Cattelani ha estudiado el violín entre 1879 y 1885 en su ciudad natal con Lodovico Mantovani. Trabajó luego como maestro de capilla en Río de Janeiro, Montevideo, Buenos Aires y Santiago de Chile. Daba clases de música en la Sociedad Italiana. En 1897 se ha constituido como director de orquesta, violinista y un organizador de conciertos en Montevideo. Compuso la ópera (Atahualpa. Murió el 16 de abril 1932 en Milán, Italia. Cfr. Publicación digital/La Floresta. Desde el barrio para el mundo, 23/06/2015. http://www.l a-floresta.com.ar/2015/junio/23.htm, consultado 19/12/2018.

58 ASSM-Zárate, Programa Año 1926, Zárate.

59 Sobre De Michelis y la construcción del teatro Coliseo de Zárate, véase Ceva, 2018.

60 El Debate, 5/11/1928, Año XXIX, No 2925, Zárate, p.1. 
Anuario del Instituto de Historia Argentina, 2020, 20(1), Mayo, ISSN: 2314-257X

CC BY-NC-SA 